\title{
Scorpion reproductive strategies, allocation and potential; a partial review
}

\author{
Michael R. WARBURG \\ Department of Biology, Technion-Israel Institute of Technology, Haifa 32000, Israel; e-mail: warburg@tx.technion.ac.il
}

Key words. Scorpiones, reproductive strategies, reproductive allocation, reproductive potential, litter size

\begin{abstract}
Most scorpion species are iteroparous, breeding more than once during their life. Some of these species are parthenogenetic. The other reproductive strategy (RS) semelparity, when scorpions breed only a single time during their life, is rare and has been documented only once. The mass allocated by the female to produce either a litter or a single offspring is the reproductive allocation (RA). It is difficult to calculate RA since the difference in female mass before and after parturition is difficult to obtain. In addition, the litter size is hardly ever accurate because of maternal cannibalism. An attempt was made to calculate RA in Nebo hierichonticus (E. Simon, 1872). Based on litter size, on breeding frequency and on longevity of the female, it is possible to estimate the reproductive potential (RP). These aspects of scorpion reproduction are reviewed and the difficulties involved in this study are discussed.
\end{abstract}

\section{INTRODUCTION}

Scorpions are a top predator among terrestrial arthropods and rarely provide prey items themselves. They are an ancient arachnid group and have not undergone any major structural modifications in recent evolutionary history. One of the reasons for their long survival are the different female reproductive systems: the apoikogenic and the katoikogenic ovariuteri (reviewed recently Warburg, 2010). These two different systems enable the use of two different reproductive modes: ovoviviparity and viviparity (M. Warburg, in prep.). In addition, two different reproductive strategies are found: semelparity (when the female breeds only a single time during its life), and iteroparity (when the female breeds more than a single time during its lifetime).

In previous studies it was shown that there are certain losses of ova and embryos during reproduction. The losses encountered during oogenesis and vitellogenesis are perhaps less interesting to the present study than the loss in embryos (in prep.). This loss is of great significance since it takes place at a rather late stage of development shortly before parturition. It involves a certain and probably major energetic waste for female reproductive allocation.

The gravid female scorpion is somewhat less active as predator during the gestation period. This implies that it has to rely on reserves stored in the hepatopancreas (M. Warburg, in prep.). This organ comprises about $40 \%$ of the body weight and is of very great significance in supplying nutrients during the long periods of oogenesis and vitellogenesis. As a result, it is almost totally depleted after birth of the young.

Very little is known about the energetics of reproduction in scorpions. Likewise, information about reproduction in the field is rather limited. Basic questions, such as the number of breeding females in the population, has hardly ever been studied under controlled conditions (in an enclosure). Likewise, in spite of information concerning litter size, available information is of limited value since in at least some of the parturitions, young were lost by providing prey to their mothers. Moreover, scant information is available about juvenile dispersal (distance, their growth in nature, and foremost their survival). What percentage survives to maturity? What is the recruitment rate? These data are essential for evaluating populations.

Scorpions are largely iteroparous. This also includes short-lived scorpion species. In addition, parthenogenesis has been shown to occur in several scorpion species. This peculiar iteroparous reproductive strategy is especially advantageous when males are rare in the population. Nevertheless, there is one recorded case when semelparity was demonstrated since the males die after mating (Varela, 1961).

As reproduction is the key factor for survival of any species, interest has increased in understanding the amount of mass allocated by the female scorpion to produce a litter. This reproductive allocation (RA) can be measured in spite of some difficulties (discussed below). As discussed previously, the main organ responsible for providing nutrients to the developing embryos in scorpions is the hepatopancreas. Since the mass lost by the hepatopancreas during embryogenesis can be measured, it is possible to convert RA into energy allocated to produce a litter.

Finally, it is theoretically possible to calculate the reproductive potential (RP) of a scorpion species by multiplying litter size by longevity. However, there are great difficulties in obtaining reliable estimates of longevity (Warburg, 2011). Likewise, rather little is known about the breeding frequency of a female. Consequently, RP calculated this way is maximal (since it assumes annual breeding which in most cases likelihood will not occur).

There are two main objectives of this study: (1) To review the literature pertaining to RA in scorpions and (2) 
determine to what extent the survival of a scorpion species is dependent on the reproductive strategy and potential.

\section{REPRODUCTIVE STRATEGY}

Scorpions are, as a rule, iteroparous animals giving birth more than once throughout their lifetime. There are two ways a scorpion can be iteroparous: sexual or parthenogenetic, the latter does not require mating (Warburg, 2001).

\section{Iteroparity}

Among iteroparous scorpions there are species that require only a single mating since they are capable of storing the spermatozoa. Other scorpions (the majority) mate more than once.

\section{Sperm storage}

In Centruroides barbudensis (Pocock, 1898), five broods have been reported after single insemination (Kovoor et al., 1987). Similarly, females of Isometrus maculatus (De Geer, 1778) are capable of giving birth to five broods without the need for new insemination (Probst, 1968, 1972). Are these species parthenogenetic or perhaps are they capable of storing sperm?

\section{Parthenogenesis}

The subject has been reviewed in recent years by Lourenço (2002) and Francke (2008). The latter identified only seven parthenogenetic species: six buthids and a liochelid species. There are seven additional species with a female-biased sex ratio. In some of these species males are so rare in the natural population that it is inconceivable that these populations can maintain themselves unless they are parthenogenetic. This raises the question of facultative parthenogenesis and the possibility of switching from one mode of reproduction (sexual) to the other (parthenogenetic). This has not yet been explored.

Makioka \& Koike (1984) and Makioka (1992, 1993) demonstrated that female Liocheles australasiae (Fabricius, 1775) reared in isolation in the laboratory, produced five successive generations in seven years. No spermatozoa were found in any region of the female reproductive system, males do not occur in these populations, and populations reproduce by thelytokous parthenogenesis (Makioka \& Koike, 1985; Yamazaki \& Makioka, 2005). Parthenogenesis was also demonstrated in Tityus bahiensis (Perty, 1833) and Tityus serrulatus Lutz \& Mello, 1922, Tityus columbianus (Thorell, 1876) (Mattihessen, 1962, 1970b, 1971; Lourenço 1991; Lourenço et al., 1996) and Tityus inexpectatus Moreno, 1940 (now Tityopsis inexpectata (Moreno, 1940) (Armas, 1980), as well as in Ananteris coineaui Lourenco, 1982 (Lourenço $\&$ Cuellar, 1999). In a more recent study Toscano-Gadea (2004) confirmed parthenogenesis in three virgin females of Tityus trivittatus Kraepelin, 1898 raised in isolation. In addition parthenogenesis was determined in Hottentotta hottentotta (Fabricius, 1787) and Hottentotta caboverdensis Lourenço \& Ythier, 2006, by raising freshly collected sub-adults in the laboratory until they moulted and gave birth (Lourenço \& Ythier, 2007). It was recently suggested that a possible cause for parthenogenesis could be infection with Wolbachia (Suedek-Rocha et al., 2006).

\section{Semelparity}

Another reproductive strategy is semelparity where females breed only once during lifetime. Semelparity is considered to be a great risk for a species since it is possible that an entire cohort (the only one produced by a female) may be lost.

It is extremely difficult to determine semelparity in animals. To be established clearly, the female needs to be raised in isolation from birth, allowed to mate and continued to be kept in isolation until death. Nevertheless, there is a single report of a semelparous scorpion based on observations on 12 female Bothriurus bonariensis (C.L. Koch 1842) kept individually in the laboratory (Varela, 1961). These females, after having mated with a male, released their larvae that hatched of the egg envelope soon thereafter (i.e. ovoviviparous). The female preyed upon the male never accepting another male again. All females died within days (averaging 20.4 days, ranging between 2-35 days) following parturition. However, the possibility that the females were stressed under laboratory conditions cannot be excluded. This is based on the report by the author himself stating that the number of juveniles released by the females was considerably smaller than that observed by him in the field.

It is likely that some of the smaller scorpion species could be semelparous since they have only one size (= generation) of oocytes in their ovariuterus. However, this will require further investigation.

To conclude, the fact that almost all scorpion species are iteroparous can indicate that there is a need for more than one breeding in order to sustain the species. This could indicate that survival of juveniles to maturity is rather low.

\section{REPRODUCTIVE ALLOCATION AND PARENTAL INVESTMENT}

\section{Reproductive allocation (RA)}

Reproductive allocation (RA), or the mass allocated by a female scorpion to produce either a litter (or a single scorpion), is an indication of the energy utilized by the female during the long period of oogenesis and embryogenesis. The calculation of RA is based on the actual difference in female body mass before and after parturition or as the percentage of original mass lost during parturition. In order to be able to calculate RA, the mass of the female before and after parturition is required. However, there are some difficulties in calculating these for the following reasons:

1. Female mass cannot be measured close to parturition since the exact date when this will take place cannot be accurately predicted. At the most, the female can be weighed daily until the onset of parturition.

2 . The female cannot be weighed directly after parturition without brushing the larvae off her back thereby endangering (even sacrificing) them. Weight can only be measured after the larvae have dismounted from the 
female usually a month following birth of the last larva. Moreover, time must be allowed in order to ascertain that parturition has come to an end. During this time the mass of the female is likely to have changed as the female may have cannibalized her larvae while giving birth (thereby gaining weight). Hence, this measurement can hardly ever be accurate.

3. The exact number of larvae is required to calculate RA. The correct litter size often cannot be measured since in some cases females cannibalize their own larvae while giving birth with the result that the correct number of larvae actually born is not known, rather the number of larvae found on the female's back (Baerg, 1961 and pers. observ.).

Consequently, this can only be an estimate of RA which is likely to be higher than the real value (as the difference in mass is divided by a conservative litter size).

There are two ways to calculate RA:

Calculating the female's body mass allocated to produce an entire brood (litter) or by determining the female's body mass allocated to produce a single juvenile.

The percentage of the female body mass allocated to produce a single larvae is derived by dividing the difference in mass by the number of juveniles in the cohort. In that case, the exact number of larvae born must be known. Due to the difficulties in determining the number of larvae actually born, it is often not possible to accurately calculate RA by this procedure.

In spite of these difficulties, an attempt was made to calculate RA both for brood and for single offspring in seven broods of Nebo hierichonticus (Table 1, Fig. $1 \mathrm{~A}-\mathrm{C})$. The difference in the female body mass female's mass before and after parturition was variable and ranged between $0.65-1.69 \mathrm{~g}$. An average $22.9 \%$ of the female mass was allocated to produce a brood and $1.42 \%$ to produce a single larva. There was a significant relationship within the litter size $\left(\mathrm{R}^{2}=0.90, \mathrm{p}<0.001\right.$ linear Fig. $\left.1 \mathrm{~A}\right)$. The difference in female mass allocated to reproduction showed no relationship with either the percentage allocated to produce a brood (Fig. 1B) or a single offspring (Fig. 1C).

\section{Parental (i.e. maternal) investment (PI)}

Parental (i.e. maternal) investment (PI) or reproductive investment (RI) includes the energy expenditure necessary to produce a brood as well as the energy needed to protect the brood while it remains on her back until after

TABLE 1. Reproductive allocation in N. hierichonticus

\begin{tabular}{lc}
\hline Average reproductive allocation per brood & $1.11 \mathrm{mg}$ \\
Average \% allocated to produce a brood & $22.9 \pm 3.1 \%$ \\
Average reproductive allocation & $0.12 \pm 0.05 \mathrm{mg}$ \\
$\quad$ to produce a larva & \\
Average \% mass allocated & $1.42 \pm 0.31 \%$ \\
$\quad$ to produce a larva & 19 \\
Number of females bearing young & $5.14 \pm 0.4 \mathrm{~g}$ \\
Average female's mass & $5-45(23.4)$ \\
\hline
\end{tabular}
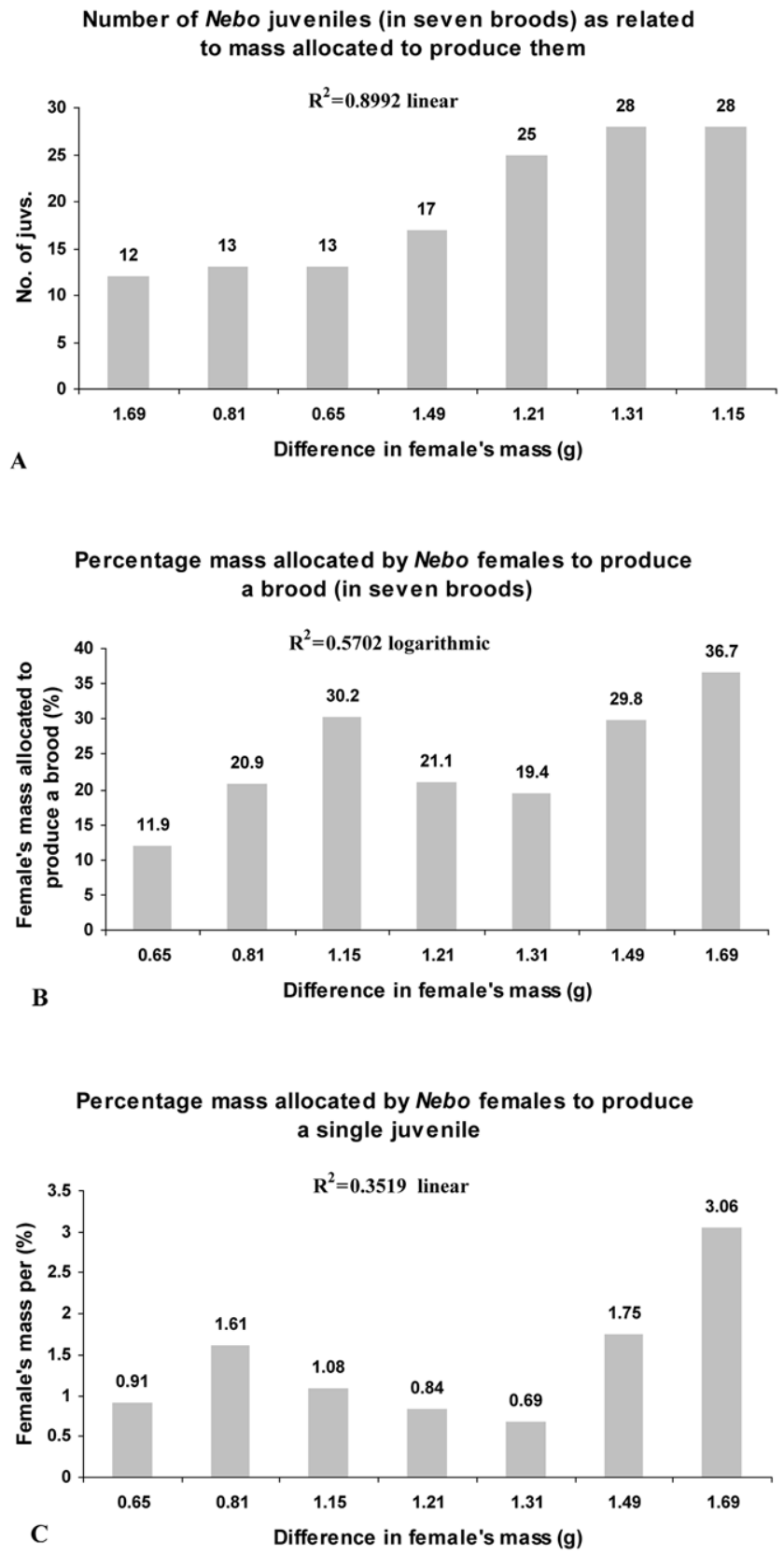

Fig. 1. Reproductive allocation (RA) in $N$. hierichonticus. The relationship between the difference in female mass $(\Delta \mathrm{g})$ allocated to produce a litter (A), and the litter size (number of juveniles) is positive. This is not seen reflected in the percentage mass allocated by the female to produce a brood (B) or a single juvenile (C).

the larval first moult. It must also take into consideration the difficulties encountered while foraging during the period following parturition until the juveniles disperse. This expenditure has not previously been considered for scorpions. Therefore, PI can only be estimated not quantified.

There a two terms which are in use but differ in their meaning:

1. Total Litter Mass (TLM) which is the mass of the litter found on the back of the female before dispersing or immediately following it (used first by Formanowicz \& 
Schaffer, 1993 who weighed the female within $16 \mathrm{~h}$ after offspring dispersal). No significant relationships were found between the female size and litter or offspring size.

2. Relative Clutch (or Litter) Mass (RCM or RLM = TLM / Fem. mass) which is the litter mass divided by female mass before parturition (Brown \& Formanowicz, 1995).

RA can also be calculated as a percentage of the original mass lost during parturition. This is the Relative Clutch (or Litter) Mass (RCM or RLM = TLM / Fem. mass) which is calculated by dividing the Total Litter Mass TLM / Female mass (see Formanowicz \& Shaffer, 1993; Brown \& Formanowicz, 1995). RA can also be given as the actual difference in female mass before and after parturition. This was determined by Brown (1997) who observed a weight decline of $472 \mathrm{mg}$ after producing 53 offspring. The variation in litter size of Centruroides vittatus (Say, 1821), and RI ranged between $56.4 \%$ to 61.8\% (Brown \& Formanowicz, 1995; Brown, 2003). There was a negative correlation between offspring size and number, and the ratio of allocation variance to investment variance within a populations. Larger females do not produce larger offspring but more offspring (Brown, 2004).

To conclude, RA varies among and within scorpion species ranging between $11.9-36.7 \%$ (averaging $22.9 \%$ in $N$. hierichonticus). In some species RA to produce a litter may amount to $61.8 \%$. To some extent, this high level of RA could cover the cost of preying on siblings. Is this inter- and intra-specific variability in RA related to different levels of maternal cannibalism? Could the female's age (i.e. the number of previous parturitions) be the cause for this variability in RA?

\section{REPRODUCTIVE POTENTIAL (RP)}

Reproductive potential (RP) is the total number of larvae (pullus) a female is capable of producing throughout her lifetime. Several questions regarding both female and litter must be considered here:

1. It is imperative to obtain exact information concerning the number of offspring produced by a single female.

2. It is essential to obtain more data on the history of previous parturitions. What is the frequency at which a female can reproduce? Does the female reproduce annually i.e. on consecutive or alternating years?

3 . What is the number of times each female breeds? Is she capable of breeding throughout her lifetime?

This information is generally lacking. Only when females are raised in captivity as in Liocheles (Makioka, $1992,1993)$ is it possible to obtain this information

In addition, in order to calculate RP an estimate of longevity is needed. However, longevity can only be estimated (in prep.).

\section{The number of offspring or litter size produced by a single female}

Litter size in nine scorpion species belonging to three families was given in Levy \& Amitai (1980), in 26 scorpion species belonging to six families (Francke, 1982; see
Relationship between S.m fuscus number of juveniles and females' mass

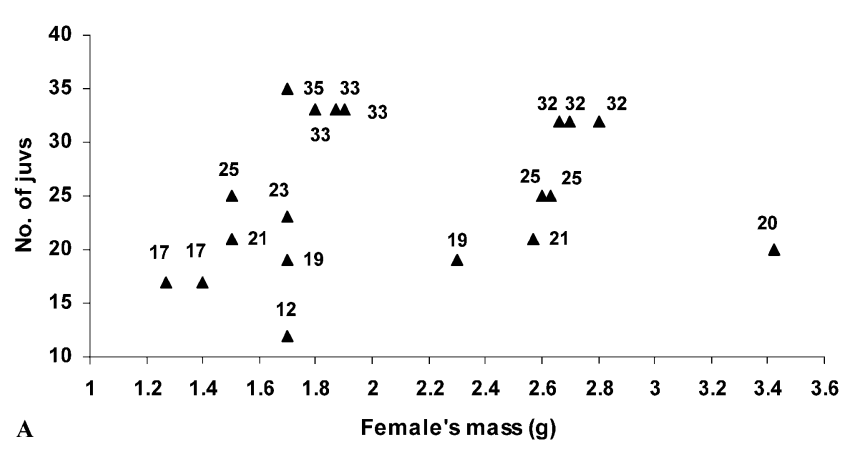

Relationship between $\boldsymbol{N}$. hierichonticus number of juveniles and females' mass

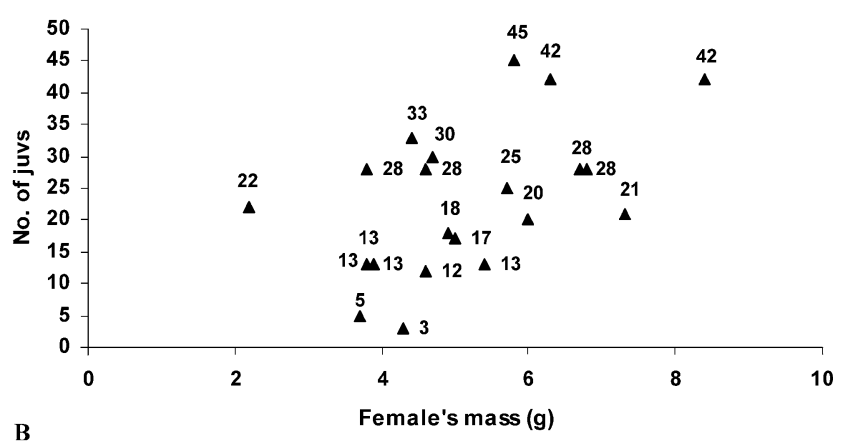

Fig. 2. Relationship between juvenile numbers of Scorpio maurus fuscus, (A), and Nebo hierichonticus (B) juveniles and female mass.

Table 1 there) and for 77 scorpion species by Polis \& Sissom (1990) updated until 1986 (see Table 4.2 there). Since these reviews were published, Mahsberg et al. (1999) provide new data on litter size in several scorpion species. A more recent review by Lourenço (2002 see Table 1 there) summarized litter size in 45 species belonging to seven families giving either averages or ranges for each species. Brown (2001, Table 1 there) provides data on clutch size for 22 buthids, seven diplocentrids, three euscorpiids, one each iurid, scorpionid and urodacid, and 16 vaejovids. A summary of average and range of litter size is provided for 21 South American species (Outeda-Jorge et al., 2009, see Table 1 there) while Mahsberg (2001) gives litter size in two scorpionids: Pandinus imperator (C.L. Koch, 1841) and Heterometrus fulvipes (C.L. Koch, 1837). Recently, Ross (2009) provides data on litter sizes for seven female Leiurus quinquestriatus H. \& E. 1829, ranging between 35-87 averaging 62.7. The data on number of larvae per brood should be taken as a conservative estimate of the actual number of larvae born.

An alternative way to estimate the reproductive potential of a single scorpion female is based on anatomical information (Warburg, 2001, 2010). In Urodacus abruptus (Pocock, 1888), Smith (1966) estimated that brood size is indeed a low estimate because of offspring lost from the mother's back. On the other hand, Brown 

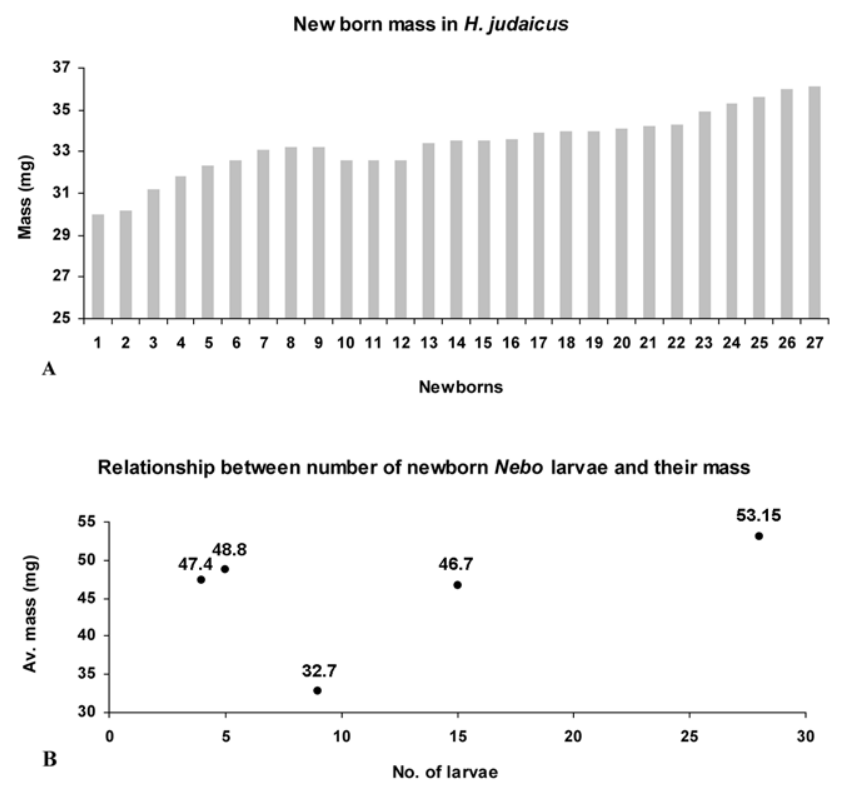

Fig. 3. Relationship between juvenile numbers of Hottentotta judaicus (A), and Nebo hierichonticus, (B) juveniles and the average juvenile mass.

(1997) found no evidence for cannibalism in Pseudouroctonus reddelli (Gertsch \& Soleglad, 1972). An alternative way to estimate litter size is by counting the number of dispersing larvae. This was done in the vaejovids and diplocentrids studied by Brown \& Formanowicz (1996).

\section{Relationship between litter size and female mass}

In some diplocentrids, litter size is proportional to the size of females (Polis \& Sissom, 1990). Likewise, Myers (2001) studying Centruroides exilicauda (Wood, 1863) (possibly Centruroides sculpturatus Ewing, 1928) found a strong correlation between maternal size and number of offspring.

The relationship between juvenile numbers of both the scorpionid Scorpio maurus fuscus (Ehrenberg, 1829) (Fig. 2A) and of the diplocentrid N. hierichonticus (Fig. 2B) show that this relationship was not significant.

\section{Relationship between litter size and offspring mass}

The relationship between brood size of both Hottentotta judaicus (E. Simon, 1872), and of N. hierichonticus, and the average juvenile mass, is shown in Fig. 3A, B respectively. In both species this relationship was not significant.

The average juvenile mass is given for nine scorpion species in Fig. 4. The average juvenile mass varied greatly among species, ranging between $1.6-45.5 \mathrm{~g}$.

\section{Loss in litter size}

Maternal cannibalism during parturition is a possible cause of loss in larvae (Polis \& Farley, 1979). Alternatively, in Smeringurus mesaensis, on average only 19.9 juveniles per brood were born possibly due to prenatal resorption of embryos when food is scarce, maternal cannibalism during parturition or sibling cannibalism (Polis \& Farley, 1979). In $S$. mesaensis sibling cannibalism of conspecifics comprises the fourth most frequent food item

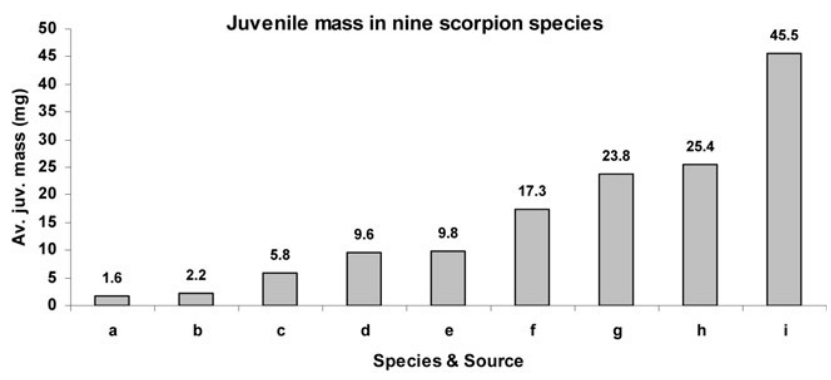

Fig. 4. Average juvenile mass in nine scorpion species. a Pseudouroctonus apacheanus (Brown, 2004), b - Vaejovis waueri (Brown \& Formanowicz, 1996), c - Pseudouroctonus redelli (Brown, 1997), d - Vaejovis spinigerus (Brown, 2004), e - Centruroides excilicauda (Brown, 2004), f - Diplocentrus lindo (Brown \& Formanowicz, 1996), g - D. peloncilennensis (Brown, 2004), h - Scorpio maurus fuscus (this study), i - Nebo hierichonticus (this study).

comprising $9 \%$ of the diet and accounting for $25 \%$ of the biomass (Polis, 1980). Newborn mortality can be explained by the fact that they provide about $16 \%$ of the adults total diet. Most newborn mortality occurs within the first 90 days of their life (Polis, 1980). Thus, a few Tityus bahiensis juveniles were observed being cannibalized by the female during parturition (Matthiesen, 1970a, b). Recently Sarmento et al. (2008) observed that $80 \%$ of female Rhopalurus rochai Borelli, 1910 were cannibalistic during parturition. My own observations (in both $N$. hierichonticus and S. m. fuscus) support this. However, the possible role of potentially stressful laboratory conditions in initiating this cannibalistic behavior cannot be excluded. In S. mesaensis, only $40 \%$ of the juveniles survive (Polis \& Farley, 1979). Sibling cannibalism of conspecifics is the 4th most frequent prey $(9 \%)$ of the diet accounting for $25 \%$ of the biomass (Polis, 1980). It was shown by Brown (1997) that $75 \%$ of a litter of 53 juveniles died during instars 2 and 3 .

This amazingly high level of newborn loss is of great significance to scorpion reproductive potential. If indeed even only a few females become cannibalistic during parturition (my own personal observations have verified this in spite of the fact that food was always available to them), and if even just one third of the litter is lost this way, then the chance of larval survival beyond the 3rd instar are rather poor indeed.

\section{HISTORY OF PREVIOUS PARTURITIONS AND PERCENTAGE OF BREEDING FEMALES IN A POPULATION}

What is the proportion of breeding females in a population? There is little information concerning this question essential to estimate population turnover. There are two ways to determine data on previous parturitions:

1. Direct method using freshly collected females (or females born and raised in the laboratory). Estimating the number of gravid females is difficult since the early stage of pregnancy cannot be detected without dissecting the female. Consequently, the data are conservative and no doubt higher in nature. Matthiesen (1970a) studying 516 female T. serrulatus, Buthidae, found $46 \%$ to be gravid. 


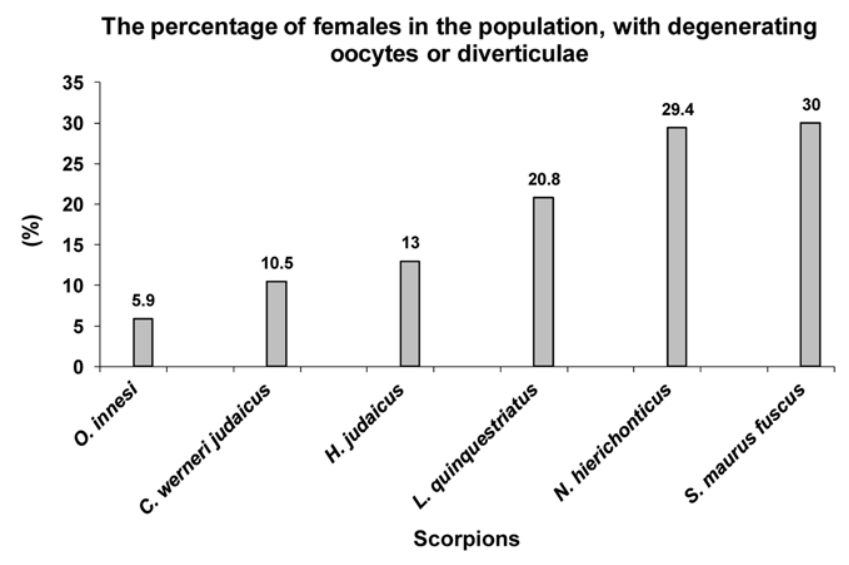

Fig. 5. The percentage of PPD calculated in females belonging to six scorpion species. In N. hierichonticus and $S . m$. fuscus, PPDs comprised almost a third of the diverticlar numbers. In the other species the percentage was lower. This could indicate that perhaps these species breed every 3 rd year whereas the others breed less frequently hence there are less PPDs. (See text for explanation of abbreviated generic names.)

The percentage of gravid females in a population was analyzed from field data on Paruroctonus (now Smeringurus) mesaensis (Stahnke, 1957), Vaejovidae, by Polis $\&$ Farley (1979). They found 41.4 to $68 \%$ of the mature females to be gravid. The only conclusion that can be drawn from these studies is that in T. serrulatus, 54\%, and in $S$. mesaensis between $32 \%-58.6 \%$ of the females were not pregnant. However these data do not provide information about the frequency of breeding in a female population as females may not breed annually.

2. Indirect method by examining ovariuteri and counting the number of degenerated (post-partum) oocytes (in apoikogenic scorpions), and that of postpartum diverticula (PPDs) in the katoikogenic scorpions (see Warburg \& Rosenberg, 1992; Warburg, 2001, 2010).

Calculating the percentage of degenerating oocytes and in six species (Fig. 5) it was found that in the apoikogenic species Orthochirus innesi (Shulov \& Amitai, 1960), Compsobuthus werneri judaicus, Hottentotta judaicus and Leiurus quinquestriatus, degenerated oocytes were found in between $5.9-20.8 \%$ of the females in a population. This fact could be an indication of the percentage of females breeding during the previous breeding season(s). The katoikogenic species, showed a much higher percentage of degenerated diverticula (PPDs) (about 30\%) indicating the percentage of females that bred during previous breeding season(s). These figures can also be an indication that only up to about $6 \%$ (in Orthochirus innesi, Shulov \& Amitai, 1960), and a maximum of 30\% (in S. m. fuscus) of the females in a population, bred previously. In other words, female $O$. innesi may breed only every sixth year of their mature life, or alternatively if short-lived, they could be semelparous, breeding only once in their lifetime. At the other end of the scale, $S . m$. fuscus females may breed only every third year thereby considerably lowering her reproductive potential. The main drawback of this method is that it cannot provide information about the chronology of the last parturitions.

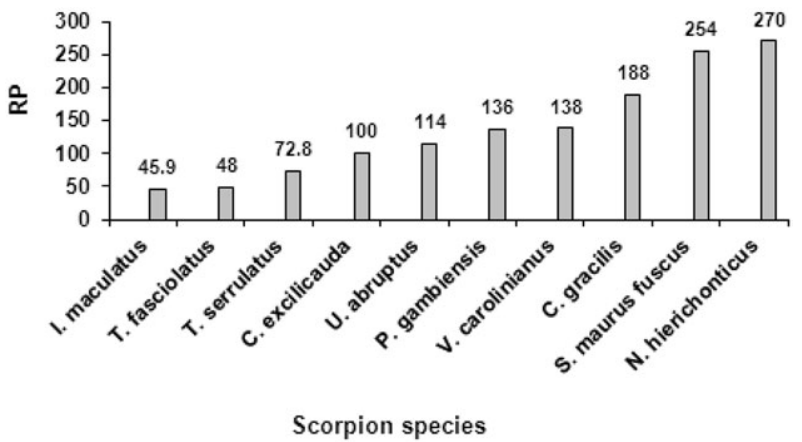

Fig. 6. Reproductive potential (RP) calculated for 10 scorpion species: Isometrus maculatus (Probst, 1968, 1972), Tityus fasciolatus (Lourenço, 2000), T. serrulatus (Matthiesen, 1971), Centruroides excillicauda (Francke \& Jones, 1982), Urodacus abruptus (Smith, 1966), Pandinus gambienisis (Vachon et al., 1970), Vaejovis carolinianus (Polis \& Sissom, 1990), C. gracilis (Francke \& Jones, 1982), S. m. fuscus (this study), N. hierichonticus (this study).

Did parturition occur during the previous breeding season? Are these remnants of several breeding seasons? Yamazaki \& Makioka (2001) found that in each of Liocheles australasiae females the number of repeated pregnancies can be traced to the number of empty (i.e. post-partum) diverticula which is roughly equal to the number of neonates.

Shorthouse (1971) dissected 35 female Urodacus yaschenkoi (Birula, 1903) and counted the number of post-partum diverticula. Half of the females $(51.4 \%)$ showed no PPDs, apparently not having reproduced during the last breeding season. This would mean that $48.6 \%$ of female $U$. yaschenkoi bred the previous year. The average number of PPDs was 13.8 PPDs (ranging between 8-31). In two females, more than double the average number of PPDs were found, thereby indicating that they had two previous parturitions (see also Shorthouse \& Marples, 1982).

\section{The RP of $N$. hierichonticus}

An attempt was made to calculate the reproductive potential in this species. (Techniques used in studying the female reproductive system are found in Warburg \& Rosenberg, 1993. In one $N$. hierichonticus female (weighing $5.74 \mathrm{~g}$ ) that gave birth to 25 juveniles and was dissected three months later, four different kinds of degenerated diverticula could be distinguished by their different coloration and length. The largest type is white measuring $5.5 \mathrm{~mm}$ long ( $3 \mathrm{~mm}$ the flagellum). This is the diverticulum which harbored the most recent embryo generation. The second type, yellowish in colour, is $4.5 \mathrm{~mm}$ long (flagellum $3 \mathrm{~mm}$ ). These diverticula contained reabsorbed embryos. The third kind of degenerated diverticula is light brown in color and shorter $(3.5 \mathrm{~mm}$ and shorter flagellum). Finally, a fourth kind of degenerated diverticulum was dark brown and half-size of the third kind. These two latter kinds of diverticula are remnants of previous parturitions that took place in previous years. Alto- 
TABLE 2. RP in an 18-years old $N$. hierichonticus female with different frequencies of parturitions.

\begin{tabular}{cccc}
\hline \multirow{2}{*}{ Age (yrs) } & \multicolumn{2}{c}{ Parturitions } & \multirow{2}{*}{ RP } \\
\cline { 2 - 3 } & Frequency (yrs) & Number & \\
\hline \multirow{2}{*}{18} & annual & 18 & 421.2 \\
& 2nd & 9 & 210.6 \\
& 3rd & 6 & 140.4 \\
& 4th & 4.5 & 105.3 \\
& 5th & 2 & 46.8 \\
\hline
\end{tabular}

gether, the ovariuterus of that female contained 25 diverticula of the first kind, 11 of the second kind, 23 of the third kind and 35 of the fourth kind. It can be concluded that this female gave birth three or four times prior to the final parturition. Since the scorpion contained two generations of small diverticula it can be assumed to be capable of giving birth at least 5-6 times with a potential total of over 100 juveniles.

A theoretical calculation of RP in an 18-year old $N$. hierichonticus female with a different numbers of parturitions is given in Table 2. The calculation assumes that the female breeds at different frequencies (ranging from annual breeding to every 5 th year). It also assumes an average litter size of 23.4. Thus, RP ranges between 46.8-421.2. To conclude, under optimal conditions, it would be sufficient for a female to breed only once since only two offspring, one of each gender, are required to survive and reach sexual maturity. The high RP is an indication that the chances of juvenile survival are not ideal.

Calculating RP for 10 scorpion species is based on data provided on putative longevity and average litter size given in the literature (Fig. 6). The data show that RP varied among the species with a low of about 45.9 and a high of 270 scorplings produced throughout their lifetime.

To conclude, theoretically, in order to sustain a species only two adults one of each gender need to reach maturity and reproduce. Nevertheless, the iteroparous scorpion breeds more than once, sometimes for several years producing a large number of offspring. This indicates that mortality among the juveniles is high and that recruitment into the population is low.

\section{SUGGESTED LINES OF RESEARCH}

1. The study of the energetic costs involved in producing a brood or a single larva.

This has been attempted only once (Shorthouse, 1971). Since the litter size is not given, the value of the data presented is limited. It is of great importance to calculate an energy balance sheet for the female from the onset of gestation to parturition. This will enable a more meaningful approach to calculating reproductive allocation. It may permit insight into turnover rates and recruitment of juveniles into the population. The correct approach to this question would be a physiological-ecological consideration. An ideal methodology could be breeding the scorpions in captivity. Isolated female scorpions need to be kept under energetically known diet conditions. Two such different diets can be used to enable comparison. The parameters to be compared concern both the female as well as the offspring, for example growth of the female and litter number as well as offspring size.

2. Although there is considerable information regarding litter size, the extent of weight loss encountered during parturition from the time of birth to juvenile dispersal, is largely unknown. This may be solved by collecting each single larva immediately after its birth, returning them later onto the mother's back and counting them again after dispersal. This should give an idea about the litter mortality during parturition.

3. To estimate recruitment rate of juveniles into the population it is important to obtain information about juvenile dispersal, age at dispersal and distance of dispersal. Studies employing enclosures are a suitable procedure.

4. The standard ecological techniques for sampling scorpions could be improved

(a) Using various methods for capturing scorpions. Each of the methods has its different advantages and drawbacks. Collecting by UV is not useful in a maqui or garigue since the thick vegetation does not enable sighting of some scorpions. It is most useful in deserts, sand dunes or prairie. Diurnal hand collecting from under refuges is useful as a supplement in areas where UV collection is not feasible and subject to the presence of refuges (stones, bark etc). Pitfall traps are not useful for capturing burrowing scorpions which employ ambush hunting strategies, rarely venturing far from the burrow opening. However, trapping can be supplemented by other two methods. Assessment of the appropriateness of capturing techniques can be achieved using an enclosure and the release of a known number of scorpions. This way the sampling efficiency, including evaluating potential sampling bias in sex ratio, can be determined. It will give one a way to evaluate population size and sex ratio since the percentage of capture will be known for each of these techniques.

(b) It is imperative to determine the percentage of breeding females in a population. This information is essential for calculating RP and can be established either by dissecting a sample of females and analyzing the ovariuteri (once a biopsy method becomes available the females do not need to be sacrificed), or by estimating the number of gravid females in an enclosure.

\section{CONCLUSIONS}

1. It is difficult to calculate RA since it is based on the difference in the mass of the female before and after parturition. These are values technically difficult to obtain. In addition, the litter size when born is rarely known with any accuracy because of maternal cannibalism.

2. RP calculation is based on knowledge of litter size and longevity of the female. The latter can only be estimated. Moreover, improved knowledge is required on the frequency of reproduction. RP is different if the female breeds every year or during alternating years.

3. The need to improve sampling techniques for population studies is emphasized. 


\section{REFERENCES}

Armas L.F. DE 1980: Aspectos de la biología de algunos escorpiones cubanos. Poeyana 211: 1-28.

BAERG W.J. 1961: Scorpions: biology and effect of their venom. Bull. Arkan. Agric. Exp. Stat. 649: 1-34.

BRown C.A. 1997: Growth rates in the scorpion Pseudouroctonis reddelli (Scorpionida, Vaejovidae). $J$. Arachnol. 25: 288-294.

Brown C.A. 2001: Allometry of offspring size and number in scorpions. In Fet V. \& Selden P.A. (eds): Scorpions. In Memoriam Gary A. Polis, British Arachnological Society, Burnham Beeches, Bucks., pp. 307-315.

Brown C.A. 2003: Offspring size-number trade-offs in scorpions: an empirical test of the van Noordwijk and de Jong model. Evolution 57: 2184-2190.

Brown C.A. 2004: Life histories of four species of scorpion in three families (Buthidae, Diplocentidae, Vaejovidae) from Arizona and New Mexico. J. Arachnol. 32: 193-207.

BRown C.A. \& Formanowicz JR. D.R. 1995: Variation in reproductive investment among and within populations of the scorpion Centruroides vittatus. Oecologia 103: 140-147.

Brown C.A. \& Formanowicz D.R., JR. 1996: Reproductive investment in two species of scorpion, Vaejovis waueri (Vaejovidae) and Diplocentrus lindo (Diplocentridae), from west Texas. Ann. Entomol. Soc. Am. 89: 41-46.

Formanowicz D.R., JR. \& Shaffer L.R. 1993: Reproductive investment in the scorpion Centruroides vittatus. Oecologia 94: $368-372$.

FrANCKE O.F. 1982: Parturition in scorpions (Arachnida, Scorpiones): a review of the ideas. Rev. Arachnol. 4: 27-37.

FRANCKE O.F. 2008: A critical review of reports of parthenogenesis in scorpions (Arachnida). Rev. Ibérica Arachnol. 16: 93-104.

Kovoor J., Lourenço W.R. \& Muñoz-Cuevas A. 1987: Conservation spermatozoides dans les voies génitales des femelles et biologie de la reproduction des Scorpions (Chélicérates). C. R. Acad. Sci. Paris 304: 259-264.

Levy G. \& Amitai P. 1980: Arachnida. Vol. 1. Scorpiones. Fauna Palaestina. Israel Academy of Science, Jerusalem, 130 pp.

LoURENÇO W.R. 1991: Parthenogenesis in the scorpion Tityus columbianus (Thorell) (Scorpiones: Buthidae). Bull. Br. Arachnol. Soc. 8: 274-276.

Lourenço W.R. 2002: Reproduction in Scorpions, with Special Reference to Parthenogenesis. European Arachnology 2000. Aarhus University Press, Aarhus, pp. 71-85.

Lourenço W.R. \& Cuellar O. 1999: A new all-female scorpion and the first probable case of arrhenotoky in scorpions. $J$. Arachnol. 27: 149-153.

Lourenço W.R., Cuéllar O. \& Méndez de la Cruz F.R. 1996: Variation of reproductive effort between parthenogenetic and sexual populations of the scorpion Tityus columbianus. $J$. Biogr. 23: 681-686.

LOURENÇO W.R.L. \& YTHeIR E.Y. 2007: Confirmation of reproduction by parthenogenesis in Hottentoata hottentota (Fabricius) (Scorpiones, Buthidae). Acta Biol. Paran. (Curitiba) 36: 213-217.

MAHSBERG D. 2001: Brood care and social behavior. In Brownell P. \& Polis G. (eds): Scorpion Biology and Research. Oxford University Press, New York, pp. 259-277.

Mahsberg D., LipPe R. \& Kalls S. 1999: Skorpione. Natur und Tier, Münster, $140 \mathrm{pp}$.

MAKIOKA T. 1992: Reproductive biology of the viviparous scorpion, Liocheles australasiae (Fabricius) (Arachnida, Scorpio- nes, Ischnuridae). II. Repeated pregnancies in virgins. Invert. Reprod. Dev. 21: 161-166.

MAKIOKA T. 1993: Reproductive biology of the viviparous scorpion, Liocheles australasiae (Fabricius) (Arachnida, Scorpiones, Ischniuridae). IV. Pregnancies in females isolated from infancy, with notes on juvenile stage duration. Int. J. Invert. Rep. Dev. 24: 207-212.

MAKIOKA T. \& KoIKE K. 1984: Parthenogenesis in the viviparous scorpion, Liocheles australasiae. Proc. Japan Acad. 60: 374-376.

MAKIOKA T. \& KoIKE K. 1985: Reproductive biology of the viviparous scorpion, Liocheles australasiae (Fabricius) (Arachnida, Scorpiones, Scorpionidae). I. Absence of males in two natural populations. Int. J. Invert. Rep. Dev. 8: 317-323.

Matthiesen F.A. 1962: Parthenogenesis in scorpions. Evolution 16: $255-256$.

Matthiesen F.A. 1970a: Reproductive system and embryos of Brazilian scorpions. Ann. Acad. Brasil Ciê. 42: 627-632.

Matthiesen F.A. 1970b: Le development post-emryonaire du scorpion Buthida: Tityus bahiensis (Perty, 1834). Bull. Mus. Natn. Hist. Nat. (2nd Ser.) 41: 1367-1370.

Matthiesen F.A. 1971: The breeding of Tityus serrulatus Lutz \& Mello 1922, in captivity (Scorpiones, Buthidae). Rev. Bras. Pesquis. Med. Biol. 4: 299-300.

MYERS C. 2001: Evolution of geographic variation in body size and life-history traits. In Brownell P. \& Polis G. (eds): Scorpion Biology and Research. Oxford University Press, New York, pp. 317-333.

Outeda-Jorge S., Mello T. \& Pinto-Da-Rocha R. 2009: Litter size, effects of maternal body size, and date of birth in South American scorpions (Arachnida: Scorpiones). Zoologia 26: $43-53$.

Polis G.A. 1980: The effect of cannibalism on the demography and activity of a natural population of desert scorpions. Behav. Ecol. Sociobiol. 7: 25-35.

Polis G.A. \& FARLEY R.D. 1979: Characteristics and environmenmtal determinants of natality, growth and maturity in a natural population of the desert scorpion, Paruroctonus mesaensis (Scorpionida: Vaejovidae). J. Zool. (London) 187: 517-542.

Polis G.A. \& Sissom W.D. 1990: Life History. In Polis G.A. (ed.): The Biology of Scorpions. Stanford University Press, Stanford, CA, pp. 161-218.

ProBst P. 1968: Mehrmalige Trächtigkeit und Dauer der Tagzeit beim Skorpion Isometrus maculatus De Geer (Fam. Buthidae). Rev. Suisse Zool. 75: 1066-1070.

Probst P. 1972: Zur Fortpflanzunsbiologie und zur Entwicklung der Giftdrüsen beim Skorpion Isometrus maculatus (De Geer, 1778) (Scorpiones: Buthidae). Acta Trop. 29: 1-87.

Ross L.K. 2009: Notes on gestation periods and litter size in the arenicolous buthid scorpion Leiurus quinquestriatus (Ehrenberg, 1828) (Scorpiones: Buthidae). J. Venom Anim. Toxins Trop. Dis. 15: 347-352.

Sarmento S.M.N., de Souza A.M., Meiado M.V. \& De AlbuQUERQUE C.M.R. 2008: Notes on the life history traits of Rhopalus rochai (Scorpiones, Buthidae) under different feeding regimes. J. Arachnol. 36: 476-479.

SHorthouse D.J. 1971: Studies on the Biology and Energetics of the Scorpion Urodacus yaschenkoi. Ph.D. Thesis, Australian National University, $163 \mathrm{pp}$.

Shorthouse D.J. \& Marples T.G. 1982: The life stages and population dynamics of an arid zone scorpion Urodacus yaschenkoi (Birula, 1903). Austr. J. Ecol. 7: 109-118. 
Smith G.T. 1966: Observations on the life history of the scorpion Urodacus abruptus Pocock (Scorpionidae), and an analysis of its home sites. Austr. J. Zool. 14: 383-398.

Suesdek-Rocha L., Bertani R., DaSilva P.I. \& Selivon D. 2006 : The first record for Wolbachia in a scorpion: the parthenogenetic yellow scorpion Tityus serrulatus (Scorpiones, Buthidae). Rev. Iber. Arachnol. 14: 183-184.

Toscano-Gadea C.A. 2004: Confirmation of parthenogenesis in Tityus trivittatus Kraepelin, 1898 (Scorpiones, Buthidae). J. Arachnol. 32: 866-869.

Vachon M., Roy R. \& Condamin M. 1970: Le développement post-embryonnaire du scorpion Pandinus gambiensis Pocock. Bull. Inst. Fr. Afr. Noire 32: 412-432.

VARELA J.C. 1961: Gestación, nacimiento y eclosión de Bothriurus bonariensis var bonariensis (Koch, 1842) (Bothriuridae, Scorpiones). Rev. Fac. Humanit. Cien. Montevideo 19: 225-244.

WARBURG M.R. 2001: Scorpion's reproductive strategies, potential and longevity; an eco-morphologist's interpretation. In Fet V. \& Selden P.A. (eds): Scorpions. In Memoriam Gary A. Polis, British Arachnological Society, Burnham Beeches, Bucks., pp. 349-358.
WARBURG M.R. 2010: The scorpion female's reproductive system; a partial review. Anat. Rec. 293: 1738-1754.

WARBURG M.R. 2011: Growth and longevity of Nebo hierichonticus kept in the laboratory; a long-term study. Bull. Br. Arachnol. Soc. (in press).

Warburg M.R. \& Elias R. 1998: The reproductive potential and strategy of Scorpio maurus fuscus (Scorpiones: Scorpionidae): anatomical clues in the ovariuterus. J. Zool. (London) 246: $29-37$.

WARBurg M.R. \& Rosenberg M. 1992. The reproductive system of a scorpion, Nebo hierichonticus (Simon 1872) (Scorpiones; Diplocentridae). Int. J. Insect Morphol. Embryol. 21: 365-368.

Warburg M.R. \& Rosenberg M. 1993: The female reproductive system in Scorpio maurus fuscus (Scorpiones: Scorpionidae). Isr. J. Zool. 39: 23-27.

YAMAZAKI K. \& MAKIOKA T. 2001: Ovarian structural features reflecting repeated pregnancies and parturitions in a viviparous scorpion, Liocheles australasiae. Zool. Sci.18: 277-282.

YAMAZAKI K. \& MAKIOKA T. 2005: Parthenogenesis through five generations in the scorpion Liocheles australasiae (Fabricius 1775) (Scorpiones, Ischnuridae). J. Arachnol. 33: 852-856.

Received August 3, 2010; revised and accepted December 6, 2010 